\title{
A ANÁLISE CRÍTICA DO DISCURSO FRENTE AOS DEBATES NO CONGRESSO NACIONAL SOBRE O NOVO CONCEITO DE FAMÍLIA
}

\author{
FERNANDA PINHEIRO DE SOUZA E SILVA ${ }^{1}$, KARL HEINZ EFKEN² \\ Universidade Católica de Pernambuco \\ Programa de Pós-Graduação em Ciências da Linguagem \\ R. do Príncipe, 526 - Boa Vista, Recife - PE, 50050-900 \\ fernandapssletras@hotmail.com , khefken@hotmail.com
}

\begin{abstract}
Resumo. Pretende-se, através desta pesquisa, refletir sobre as orientações ideológicas que norteiam algumas revistas e portais acerca da questão da aprovação ou não do novo conceito de família no Congresso Nacional. Optou-se por investigar esses embates por ser um evento discursivo polêmico e atual que se instala no Congresso e na sociedade, além de o assunto ser constituído de luta e de poder-pontos chaves para o estudo da manipulação discursiva. As análises visam compreender, identificar e comparar as estratégias linguísticas e discursivas em função de questões políticas e ideológicas das instituições jornalísticas. Este artigo apresentará a análise de duas instituições midiáticas: a editora Globo, representada pela Revista Galileu e a Revista Gospelmais, de cunho evangélico. Para fundamentação, lançamos mão da Análise Crítica do Discurso como referencial teórico e metodológico de forma a examinar as construções discursivas relativas ao abuso de poder.
\end{abstract}

Palavras-chave: Análise Crítica do Discurso; discurso da mídia; conceito de família.

\begin{abstract}
It is intended, through this research, to reflect on the ideological guidelines that guide some magazines and portals about the issue of whether or not the new concept of family is approved in the National Congress. We opted to investigate these clashes because it is a controversial and current discursive event that takes place in Congress and in society, in addition to the subject being constituted of struggle and power-key points for the study of discoursive manipulation. The analyses aim to understand, identify and compare linguistic and discursive strategies according to political and ideological issues of journalistic institutions. This article will present the analysis of two media institutions: the Globo publisher, represented by Galileu Magazine and the Gospelmais Magazine of an evangelical nature. For the theoretical foundation, we used Critical Discourse Analysis as a theoretical and methodological framework in order to examine the discursive constructions related to the abuse of power.
\end{abstract}

Keywords: Critical Discourse Analysis; media speech; family concepts.

\footnotetext{
${ }^{1}$ Doutoranda em Ciências da Linguagem pela UNICAP (Universidade Católica de Pernambuco).

${ }^{2}$ Doutor em Filosofia pela PUC-RS. Docente e pesquisador na Universidade Católica de Pernambuco.
} 


\section{INTRODUÇÃO}

Esta pesquisa foi fruto da minha dissertação e tem como base a investigação de posicionamentos discursivos e ideológicos de instituições midiáticas, visando ao seguinte tema: a implementação ou não do Estatuto da Família no Congresso. Esse tema foi eleito por nós em função de estar em ampla discussão no Congresso e na sociedade. Sobre isso, o deputado, pernambucano e evangélico, Anderson Ferreira elaborou um Projeto de lei PL 6583/13 - com o propósito de valorizar a família brasileira implementando políticas públicas em prol dessa instituição e manter a definição antiga do conceito de família. $\mathrm{O}$ deputado defende que essa instituição é, e deverá ser caracterizada pela união entre homem e mulher por meio de casamento ou união estável ou o núcleo formado por um dos pais mais os filhos, excluindo as demais configurações familiares. Contrapondo a essa definição tradicional, há um grupo de parlamentares que defende uma concepção plural de família. São elas: famílias estendidas (com parentes, como avôs), famílias compostas (com amigos), famílias monoparentais (uma única pessoa) e famílias homoparentais (homossexuais).

O evento social a ser discutido tem como sujeitos antagônicos, segundo o discurso jornalístico, a bancada evangélica e a bancada não evangélica. $O$ termo frente parlamentar (ou bancada) designa um grupo de membros dos poderes legislativos federal, estaduais e municipais, que tem sua atuação unificada, em função de interesses comuns, independentemente do partido político a que pertençam. Este estudo, que engaja os pesquisadores enquanto sujeitos ativos e comprometidos, tem como objetivo identificar estratégias linguístico-discursivas mediáticas utilizadas para a construção de determinados posicionamentos políticos, interpretando-os em termos de construção ideologicamente orientada de sentidos a favor ou contra a implementação do PL 6.583/13.

Segundo Meurer (2004), a qualidade do conhecimento construído sobre os acontecimentos noticiados pela mídia interfere no posicionamento do leitor. Norman Fairclough (2003) esclarece que as práticas sociais são realizadas, perpetuadas e modificadas por meio de discursos. Isto acontece especialmente na sociedade atual em que o constante processo de democratização - com as garantias dos direitos individuais e com as leis cada vez mais rígidas - torna simbólico um meio importantíssimo para a coerção, por um lado, e para a luta, por outro, em detrimento da força e da violência físicas.

As instituições escolhidas para coleta de textos foram as seguintes revistas: Carta Capital, Gospelmais, Forum, Galileu, Veja, Istoé e Carta Maior. Além disso, investigamos também os portais Câmara Notícias e Agência Brasil. Elas foram escolhidas por vários motivos, dentre eles, podemos destacar que essas instituições deveriam trazer pontos de vistas distintos para veicular o favorecimento ou a oposição ao Estatuto e são revistas com grandes visualizações na internet. Na dissertação, trabalhei com um corpus restrito e um ampliado, esse último ajudou a lançar luz sobre os textos do corpus restrito, sobre o que se queria investigar - por exemplo, o fato de uma reportagem ter sido anunciada na capa ou retomada em outros textos ao longo da mesma edição pode revelar uma maior atenção dada a um determinado assunto pela revista. Outra função do corpus ampliado é indicial, ou seja, de embasar afirmações fora da análise, como a história das revistas de apoio ou rejeição ao Estatuto. Entretanto, este artigo apresentará apenas a análise de duas instituições midiáticas: a editora Globo, representada pela Revista Galileu 
e a Revista Gospelmais, de cunho evangélico que apresentam pelo corpus ampliado estudado compromissos ideológicos díspares.

\section{PANORAMA DA ANÁLISE CRÍTICA DO DISCURSO E OS SIGNIFICADOS DO DISCURSO}

A Análise Crítica do Discurso estuda textos e eventos em diversas práticas sociais, propondo uma teoria e um método para descrever, interpretar e explicar a linguagem em contextos sócio-históricos. O tema a ser investigado neste artigo é polêmico e, de certa forma, de vanguarda para os padrões atuais, pois, diz respeito a uma mudança milenar sobre o conceito bíblico de família. Segundo Chouliaraki e Fairclough (1999) a ACD está situada na ciência social crítica e na pesquisa crítica sobre a mudança social na sociedade moderna posterior. O termo 'modernidade posterior' é usado por Anthony Giddens (1991), com referência às transformações econômicas e socioculturais das três últimas décadas do século XX, em que os avanços na mídia e na tecnologia da informação apartaram os signos de sua localização específica permitindo sua livre circulação nos limites temporais e espaciais. Esse conceito é escolhido aqui, embora possa ser ultrapassado em determinadas pesquisas, por estar diretamente contextualizado com as transformações que as identidades familiares passam. A reflexividade institucional, sendo uma característica dessa modernidade tardia, promove o choque entre o tradicional e o atual, e consequentemente, promove a reflexividade almejada e, de certa forma, democrática.

Norman Fairclough (2001) operacionaliza três dimensões na abordagem do discurso: análise dos textos, análise das práticas discursivas e análise das práticas sociais. A análise do discurso, dentro desse modelo, ocorre de forma simultânea nas três dimensões, ou seja, uma não é obrigatoriamente priorizada em relação à outra. Essa abordagem constitutiva do discurso é baseada na Gramática Sistêmico-Funcional de Michael Alexander Kirkwood Halliday (1985), no qual apresenta as três macro-funções da linguagem: ideacional, interpessoal e textual. Norman Fairclough (2003) reelabora essas funções e propõe uma articulação entre as macro-funções de Halliday e os conceitos de gênero, discurso e estilo. $\mathrm{O}$ autor sugere, no lugar das funções da linguagem, os três principais tipos de significado: o significado acional, o significado representacional e o significado identificacional. O Linguista argumenta que o discurso figura através das três principais formas discursivas, como parte de práticas sociais na relação entre textos e eventos, sendo assim distribuídos: modos de agir, modos de representar e modos de ser. A cada um desses modos corresponde um significado. O significado acional (gênero) focaliza o texto como modo de (inter)ação em eventos sociais; o significado representacional (discurso) enfatiza a representação de aspectos do mundo em textos; e o significado identificacional (estilo) refere-se à construção e à negociação de identidades no discurso. Será utilizado para análise as categorias analíticas que atendem ao estudo dos três significados, a saber: (a) significado acional: gênero discursivo e intertextualidade; (b) significado representacional: interdiscursividade e léxico; (c) significado identificacional: modalização. É importante destacar que esses significados atuam nas dimensões textuais, discursivas e da prática social formando a teoria tridimensional do discurso defendida por Norman Fairclough. 


\section{SIGNIFICADO ACIONAL, GÊNERO E INTERTEXTUALIDADE}

Segundo Fairclough (2003), os gêneros são formas particulares de relações sociais entre agentes sociais. Para a ACD, a análise de gêneros engloba o papel dos gêneros nas ações e interações que ocorrem em eventos sociais. Quando se analisa um texto em termos de gênero, a intenção é verificar como o texto figura na interação social e como contribui para ela em eventos sociais concretos (RESENDE; RAMALHO, 2014, p. 62), assim, as práticas sociais definem gêneros específicos.

Quanto a intertextualidade, Fairclough (2003) adverte que não pode haver enunciado que não remeta a outro enunciado. De acordo com ele, os enunciados são inerentemente intertextuais, constituídos por elementos de outros textos. Sendo assim, intertextualidade pode ser tida como a presença ou combinação de outras vozes no texto, citadas diretamente ou não. A detecção dessas vozes será feita pelo reconhecimento dos discursos direto, indireto - seja em forma de paráfrases e citações.

\section{Significado representacional, interdiscursividade e léxico}

O significado representacional está conectado às formas particulares de retratar aspectos do mundo e, também, está associado ao discurso. Diversos discursos possuem diferentes perspectivas de observar o mundo e, sendo assim, ligam-se a campos sociais distintos. Em relação ao campo que este trabalho se insere, o midiático, é preciso compreender a função de destaque das mídias como instrumento de lutas hegemônicas, que possibilitou grupos cada vez mais restritos a disseminarem seus discursos, suas visões de mundo.

Quanto a interdiscursividade, Fairclough (2003) afirma que ela pode ser considerada uma categoria analítica do significado representacional por representar aspectos do mundo, ou seja, para essa categoria o analista volta sua atenção para os discursos articulados ou não nos textos.

\section{Significado identificacional, estilo e modalidade}

O significado identificacional está relacionado ao conceito de estilo por constituir-se no processo discursivo de identidades, ou seja, no processo de identificação de atores sociais. A linguagem enquanto discurso é um modo de identificar a si e ao outro. Ela contribui, como assegura Fairclough (2003), para a constituição de modos particulares de ser, isto é, para a formação de identidades sociais ou pessoais. Nesta pesquisa, será investigado também como as instituições midiáticas se posicionam quanto ao tema do Conceito de Família. Utilizar-se-á para esta apuração os modalizadores, como por exemplo, os advérbios. Fairclough (2003) define, assim, modalidade como sendo o julgamento do falante sobre as probabilidades ou obrigatoriedades envolvidas no que ele afirma. 


\title{
CONCEPÇÃO DE PODER/HEGEMONIA E IDEOLOGIA
}

Fairclough (2001) utiliza a concepção de hegemonia de Gramsci e a concepção da evolução das relações de poder como luta hegemônica. Ele dá a seguinte definição para esta relação:

\begin{abstract}
Hegemonia é liderança tanto quanto dominação nos domínios econômico, político, cultural e ideológico de uma sociedade. Hegemonia é poder sobre a sociedade como um todo de uma das classes economicamente definidas como fundamentais em aliança com outras forças sociais, mas nunca atingido senão parcial e temporariamente, como um 'equilíbrio instável'. Hegemonia é a construção de alianças e a integração muito mais do que simplesmente a dominação de classes subalternas, mediante concessões ou meios ideológicos para ganhar seu consentimento. (FAIRCLOUGH, 2001, p. 122)
\end{abstract}

Nesse sentido, Gramsci (1971) afirma que as lutas hegemônicas pelo poder estão baseadas em mudança de foco das relações de dominação, às quais passaram a ser mais calcadas no consentimento ao invés de ter como base a coerção. Quanto às ideologias, para Fairclough (2001), elas são significações da realidade construídas nas várias dimensões de poder.

\section{METODOLOGIA}

A pesquisa compreende dois momentos: no primeiro, ocorre a seleção de textos que necessariamente constroem sentidos a favor e contra o Estatuto da Família, de modo que a própria seleção desses textos já faz parte da análise; no segundo momento, são identificadas e analisadas as estratégias linguístico-discursivas que criaram esses efeitos. Não se pode perder de vista, no entanto, que essas duas situações não são autônomas e nem seguem uma ordem fixa. Por mais objetiva que a pesquisa pretenda ser, o pesquisador-leitor, assim como qualquer outro sujeito, é constituído de ideologias e posicionamentos. A leitura do texto de uma revista não pode estar (e não está) desvinculada da leitura do texto da outra, como se fosse a primeira leitura, de maneira que a identificação e a comparação acontecem simultaneamente na análise.

\section{Sobre o corpus e as categorias de análise}

Para compor o corpus restrito foram utilizados sete textos e selecionado outros treze para o corpus ampliado. O corpus restrito é composto pelos textos sobre os quais a análise incidiu diretamente, de onde se observou as estratégias linguístico-discursivas em função da construção de sentido. E o corpus ampliado, como já mencionado anteriormente, é composto de textos que foram vistos pelo lado do comprometimento ideológico de cada instituição.

Seguem abaixo dois quadros, sendo um com o corpus restrito e o outro com o corpus ampliado: 


\begin{tabular}{|c|c|c|c|}
\hline Revista/Portal & Título & Gênero Textual & Data de publicação \\
\hline Veja & $\begin{array}{l}\text { A família, um homem e uma } \\
\text { mulher, a democracia, os gays e } \\
\text { as heterodoxias constitucionais. }\end{array}$ & Artigo de opinião & $25 / 09 / 2015$ \\
\hline Forum & $\begin{array}{l}\text { Erika Kokay: "O que define família é } \\
\text { o amor". }\end{array}$ & Artigo de opinião & $22 / 08 / 2015$ \\
\hline Carta Capital & $\begin{array}{l}\text { Até Jesus ficaria de fora do Estatuto } \\
\text { da Família de Cunha. }\end{array}$ & Artigo de opinião & $28 / 09 / 2015$ \\
\hline Câmara Notícias & $\begin{array}{l}\text { Câmara aprova Estatuto da família } \\
\text { formada a partir da união de homem e } \\
\text { mulher. }\end{array}$ & Notícias & $08 / 10 / 2015$ \\
\hline Galileu & $\begin{array}{l}\text { Uma lei pode determinar o que } \\
\text { significa família? }\end{array}$ & Artigo de opinião & $28 / 05 / 2015$ \\
\hline Gospelmais & $\begin{array}{l}\text { Aprovado, relatório do Estatuto da } \\
\text { Família reconhece apenas a união de } \\
\text { homem e mulher. }\end{array}$ & Notícia & $03 / 09 / 2015$ \\
\hline Istoé & $\begin{array}{l}\text { O Estatuto da Família é um } \\
\text { retrocesso. }\end{array}$ & Entrevista & $28 / 10 / 2015$ \\
\hline
\end{tabular}

\section{Quadro 1: corpus restrito.}

\begin{tabular}{|c|l|c|c|}
\hline Revista/Portal & \multicolumn{1}{|c|}{ Título } & Gênero textual & Data de publicação \\
\hline Forum & $\begin{array}{l}\text { Ativistas se mobilizam nas redes } \\
\text { contra Estatuto da Família. }\end{array}$ & Notícia & $24 / 02 / 2015$ \\
\hline Forum & $\begin{array}{l}\text { A inconstitucionalidade do Estatuto } \\
\text { da Família. }\end{array}$ & Artigo de opinião & $27 / 07 / 2015$ \\
\hline Forum & $\begin{array}{l}\text { Definição de família é aprovada por } \\
\text { comissão como "união entre homem } \\
\text { e mulher". }\end{array}$ & Notícia & $24 / 09 / 2015$ \\
\hline Carta Capital & $\begin{array}{l}\text { As vítimas da "sagrada família" que } \\
\text { o Congresso quer criar. }\end{array}$ & Artigo de opinião & $11 / 03 / 2015$ \\
\hline Carta Capital & $\begin{array}{l}\text { Estatuto da Família afugenta casais } \\
\text { homossexuais da fila de adoção. }\end{array}$ & Reportagem & $28 / 04 / 2015$ \\
\hline Carta Capital & $\begin{array}{l}\text { As vítimas das trevas do Estatuto da } \\
\text { Família. }\end{array}$ & Reportagem & $23 / 10 / 2015$ \\
\hline
\end{tabular}




\begin{tabular}{|c|c|c|c|}
\hline Istoé & $\begin{array}{l}\text { Pressionados } \\
\text { conservadorismo, deputados adiam } \\
\text { a aprovação do código que } \\
\text { representa um avanço no direito } \\
\text { brasileiro. }\end{array}$ & Entrevista & $02 / 09 / 2015$ \\
\hline Agência Brasil & $\begin{array}{l}\text { Relator apresenta hoje substituto } \\
\text { sobre Estatuto da Família. }\end{array}$ & Reportagem & $02 / 09 / 2015$ \\
\hline Agência Brasil & $\begin{array}{l}\text { Católicos e evangélicos divergem } \\
\text { na Câmara sobre Estatuto da } \\
\text { Família. }\end{array}$ & Reportagem & $25 / 06 / 2015$ \\
\hline Gospelmais & $\begin{array}{l}\text { Jean Willys ataca pastores Feliciano } \\
\text { e Malafai: "oportunistas, canalhas e } \\
\text { fundamentalistas". }\end{array}$ & Notícia & $26 / 06 / 2015$ \\
\hline Veja & $\begin{array}{l}\text { Fachin a mente divinal por trás de } \\
\text { propostas que transformam a } \\
\text { família na casa da mãe joana. }\end{array}$ & Artigo de opinião & $30 / 04 / 2015$ \\
\hline Carta Maior & $\begin{array}{lllr}\text { A felicidade } & \text { por } & \text { decreto: } & \text { o } \\
\text { medievalismo } & \text { do } & \text { Estatuto } & \text { da } \\
\text { Família. } & & & \end{array}$ & Artigo de opinião & $16 / 03 / 2015$ \\
\hline Carta Maior & 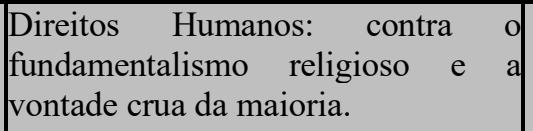 & Artigo de opinião & $02 / 04 / 2015$ \\
\hline
\end{tabular}

Quadro 2: corpus ampliado.

As categorias a serem analisadas vão do nível macro/social ao micro/linguístico e são representadas pela intertextualidade, interdiscursividade, gênero discursivo, léxico e modalidade. Elas representam os três significados do discurso: o acional, o gênero discursivo e a intertextualidade; o representacional: a interdiscursividade e o léxico; e o identificacional, a modalidade.

Muito produtivamente, essas categorias podem revelar informações subtendidas de manipulação do leitor, por ser um espaço linguístico-discursivo flexível, em que o interlocutor possui escolhas. Seguem abaixo os conceitos atinentes às categorias a serem identificadas e analisadas:

(a) Gênero discursivo: Fairclough \& Chouliaraki (1999) defendem a ideia de que gênero é um conjunto estável de convenções no qual se associa a um tipo de atividade ratificada socialmente;

(b) Intertextualidade: $\mathrm{O}$ intertexto é toda referência a outros textos, por citação ou por transcrição;

(c) Léxico: Pode ser feito por nomeação e adjetivação. Os nomes estão a serviço do querer-dizer do sujeito, a serviço dos objetivos comunicativos e ideológicos dele; 
(d) Interdiscursividade: Diversos discursos particulares associam-se a campos sociais, interesses e projetos particulares, por isso podemos associar discursos particulares a determinadas práticas;

(e) Modalidade: Assim como a adjetivação, a modalidade, dentro de uma elaboração discursiva, descreve ações, possíveis e reais, para caracterizar a realização dos eventos.

\title{
ANÁLISE DOS GÊNEROS MIDIÁTICOS: REVISTA GOSPELMAIS E FORUM
}

A. Revista Gospelmais de 03 de setembro de 2015.

\author{
Aprovado, relatório do Estatuto da Família reconhece \\ apenas a união de homem e mulher \\ Por Tiago Chagas, 3 de setembro de 2015.
}

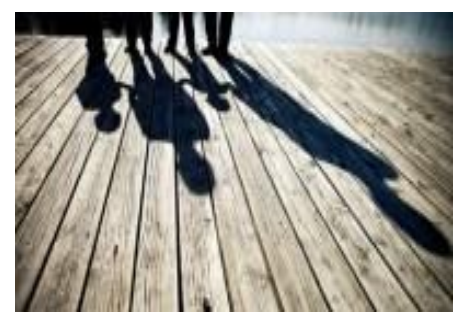

O projeto de lei apelidado como Estatuto da Família teve seu relatório aprovado na comissão especial que estuda o texto, e manteve o conceito familiar como relator do projeto, deputado federal Diogo Garcia (PHS-PR) afirmou em seu parecer que uma família é "a união de um homem e de uma mulher, por meio de casamento ou de união estável, e a comunidade formada por qualquer dos pais e seus filhos". A divulgação do parecer aconteceu na última quarta-feira, 02 de setembro. Para os críticos do projeto, seu texto é considerado equivocado por não considerar família as uniões entre pessoas do mesmo sexo e as relações poligâmicas, por exemplo. Outro argumento usado é a decisão do Supremo Tribunal Federal (STF) de proibir os cartórios de se recusarem a celebrar o casamento civil ou converter união estável em casamento de homossexuais.

Garcia, ciente das críticas, usou um contra-argumento no relatório do projeto: "Trata-se de competência do Congresso Nacional regulamentar, para maior eficácia, a especial proteção constitucionalmente garantida à família. $\mathrm{O}$ estatuto vem para colocar a família, base da sociedade, credora de especial proteção, no plano das políticas públicas de modo sistemático e organizado, como até então não se fizera. Nada impede que os cidadãos, mediante seus representantes políticos, advoguem pela inclusão de novos benefícios a outras categorias de relacionamento, mediante argumentos que possam harmonizar-se à razão pública".

Por fim, o parlamentar destacou que seu relatório foi formado a partir das impressões colhidas durante os debates e as audiências públicas, quando ouviu representantes da sociedade. O documento, segundo ele, está "alinhado aos preceitos constitucionais e valores morais e éticos de nossa sociedade, com o fim de garantir direitos e o desenvolvimento de políticas públicas para a valorização da família”.

A partir desse momento, será analisada a notícia apresentada: 
1. Gênero discursivo: O título da notícia é iniciado pelo particípio do verbo aprovar: "aprovado", em seguida, há uma pausa intencional evidenciada pela vírgula com o intuito de informar primeiramente o resultado do Estatuto da Família, que foi aprovado, e posteriormente a complementação dessa aprovação, ou seja, foi aprovado o Estatuto que reconhece família apenas a união de homem e mulher. Não há um título auxiliar, uma vez que, no título principal já existem duas informações que o portal Gospelmais quer transmitir. O primeiro parágrafo possui as duas informações principais, quais sejam: a aprovação do Estatuto e a essência dele que é a formação de família segundo um conceito tradicional. O corpo da notícia reforça essa ideia e informa que o Estatuto é defendido pela bancada evangélica, informação muito relevante posto que, o público ao qual se destina a notícia são os leitores do portal GospelMais, ou seja, evangélicos ou simpatizantes com essa ideologia.

2. Intertextualidade: A única voz expressa pela citação direta é a do deputado Diego Garcia, relator do Estatuto, que vem para legitimar a notícia. Outras vozes, que têm essa função de legitimação, aparecem quando o portal remete o Estatuto ao seu criador, o deputado Anderson Ferreira, e ao apoio da bancada evangélica. Todas essas vozes referidas anteriormente estão comprometidas com o Estatuto da Família de Anderson Ferreira. No penúltimo e último parágrafo surge a referência do portal a outras vozes que contra-argumentam com o discurso do Estatuto. Em referência aos partidos de apoio ao governo, somente diz que seus posicionamentos não defendem o Estatuto.

3. Léxico: A notícia foi pequena e seu texto resumiu-se a duas informações básicas já citadas e comentadas anteriormente: a aprovação do Estatuto e o reconhecimento de família como oriunda da união entre um homem e uma mulher. Há, nesta notícia, o excesso de emprego do verbo ser na forma conjugada do presente do indicativo "é”, como seguem as orações: “(...) família é 'a união de um homem e mulher"”; "O Estatuto da Família (...) é apoiado pelos parlamentares da bancada evangélica (...)"; " Para os críticos do projeto, seu texto é considerado equivocado por não considerar família a união entre pessoas do mesmo sexo (...)". Esse emprego do verbo conjugado "é" acontece tanto na argumentação quanto na contra-argumentação. Pode-se refletir sobre isso como sendo uma estratégia linguística do portal, dado que essa utilização do verbo ser dá ideia de estado de permanência, algo que não se pode mais alterar ou mudar.

4. Interdiscurso: O portal Gospelmais identifica-se por completo com o discurso religioso e com a conduta dos seus políticos promovendo uma junção de discursos. De acordo com Machado (2012), os políticos evangélicos dão maior relevância à identidade religiosa em detrimento das identidades partidárias que, pelo menos a princípio, deveriam orientar as condutas políticas no sistema da democracia representativa. Observa-se, nesta notícia, no terceiro parágrafo, um indício do que Machado (2012) assevera: “O Estatuto da Família é apoiado pelos parlamentares da bancada evangélica (...)". Ou seja, por que é relevante mencionar a aprovação dessa comunidade?

5. Modalidade: A modalidade epistêmica (no sentido de comprometimento com a verdade) empregada pelo Portal Gospelmais, sendo expressa pelo verbo ser na 
forma conjugada "é”, aparece em todos os parágrafos dando ideia, como já comentado, de estado permanente dos sujeitos. Como exemplo: “(...) família é a união de um homem e de uma mulher(...)". Ou seja, está definido por lei que não há espaço para outro tipo de família que não seja a tradicional e cristã.

B. Viés da editora Confiança com a revista Carta Capital, de 28 de setembro de 2015.

Revista Carta Capital, 28 de setembro de 2015

\section{Até Jesus ficaria de fora do Estatuto da Família de Cunha}

\section{Projeto é mais um episódio da cruzada contra os direitos individuais dos deputados religiosos e oportunistas \\ Por Mauricio Moraes — publicado 28/09/2015 08h56}

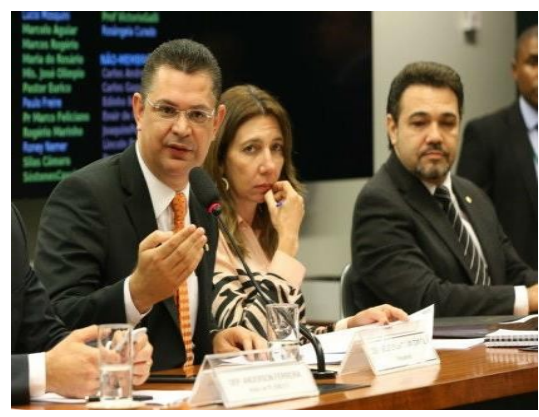

Retrocesso: Sóstenes Cavalcante (PSD-RJ) e Marco Feliciano (PSC-SP) durante a sessão em que o Estatuto da Família foi aprovado.

Jesus, segundo consta, era filho de uma virgem, concebido por um Espírito Santo. Maria, sua mãe, a mais nova e retrógrada legislação concebida pelos fundamentalistas do Congresso Nacional, capitaneados pelo suposto cristão Eduardo Cunha (PMDB-RJ). O tal Estatuto da Família é mais um capítulo da cruzada contra os direitos individuais que viceja em um Congresso pautado, cada vez mais, por deputados religiosos (e oportunistas). O texto, aprovado na Comissão de Constituição e Justiça da Câmara Federal, considera família vivia com um carpinteiro, José, que se tornou o segundo pai do menino. Em suma, se vivessem no Brasil de 2015, estariam sob risco de ficar de fora do tal Estatuto da Família, a união única e exclusiva entre um homem e uma mulher. Famílias homoafetivas ou poliafetivas (caso da de Jesus, diga-se) estariam, em tese, fora da lei (...) Tudo isso se dá logo após os mesmos fundamentalistas conseguirem barrar, País afora, a inclusão nos Planos Municipais de Educação do debate sobre a questão de gênero nas escolas. Falar sobre gênero é combater o machismo que endossa a violência sexual que as mulheres vivem no seu dia a dia. É combater bullying nas escolas, que faz com que adolescentes LGBT estejam no topo dos rankings de suicídios. Ou seja, falar sobre gênero é falar sobre tolerância. E a pressão dos religiosos foi tão grande que até inventaram um termo, a tal "ideologia de gênero", uma mentira que ganhou ares de verdade no debate raso dos conservadores.

Na Comissão de Constituição e Justiça, o Estatuto da Família foi aprovado com os votos do PSDB, do PV, do PSC, do PSB, do PSD, do Solidariedade, do PP, do DEM. Votaram contra apenas o PT, o PSOL, o PCdoB e o PTN. (...) 
Mas é bom lembrar que está justamente aí o ovo da serpente. Há poucos anos, ninguém poderia imaginar que em pleno século 21 deputados e senadores estivessem mais ocupados em legislar sobre o corpo alheio do que sobre questões que realmente importam para o País. Mas aí vieram os deputados pastores, irrigando campanhas com dízimo que não paga imposto e querendo cada vez mais espaço. O resultado está aí: Eduardo Cunha, um dos mais insólitos representantes do conservadorismo religioso brasileiro, na presidência do Legislativo Nacional.

Não se enganem... Depois de conquistarem a mídia, pautarem o Congresso, os fundamentalistas religiosos, logo mais, darão o próximo passo fazer lobby para a indicação do primeiro ministro evangélico do STF. Tempos obscuros.

A partir daqui, será analisado o artigo de opinião apresentado:

1. Gênero discursivo: O gênero adotado para discursar sobre o Estatuto da Família, pela revista Carta Capital referente ao dia 28 de setembro de 2015, foi o artigo de opinião do jornalista Maurício Moraes. O título, "Até Jesus ficaria de fora do Estatuto da Família de Cunha", aliado ao título auxiliar, "Projeto é mais um episódio da cruzada contra os direitos individuais dos deputados religiosos e oportunistas", já denotam a perspectiva ideológica a que será direcionado esse artigo, ou seja, no sentido dos que defendem um estatuto contrário ao defendido por Eduardo Cunha, dos que defendem um estatuto com uma formação diversificada de família. Em outros artigos e notícias da Carta Capital, que serviram de corpus ampliado para a verificação da tendência discursiva e ideológica da revista, percebeu-se que lá também incide uma ideologia seguindo ao encontro com a definição de família plural. O primeiro parágrafo explica a citação de Jesus no título, colocando-O como pertencente, na época, a uma família nada tradicional, uma vez que José era considerado o segundo pai de Jesus. O segundo parágrafo confirma o primeiro, afirmando que o Estatuto é mais uma forma de ação contra os direitos individuais humanos. $\mathrm{O}$ artigo segue acusando os fundamentalistas, conservadores do Congresso que insistem em negar mudanças nas sociedades contemporâneas.

2. Intertextualidade: A voz que se destaca no artigo analisado é a da revista Carta Capital que é representada pelo jornalista. A todo momento a opinião do jornalista foi posicionada de forma argumentativa. Ele, no primeiro parágrafo, utiliza a citação indireta da Família Sagrada para identificá-los como uma família não tradicional e, logo em seguida, o jornalista sugere a hipótese de poder se pensar ser desrespeitosa essa ligação, porém, informa que se trata de discutir o desrespeito do Congresso atual com parte considerável da sociedade brasileira. Maurício Moraes cita o Projeto de lei 5069/2013 - de Cunha - que não protege a mulher, vítima de estupro, na tentativa de apresentar muitos argumentos para tornar Cunha réu.

3. Léxico: O trecho "O tal Estatuto é mais uma cruzada contra os direitos individuais que viceja um Congresso, cada vez mais, por deputados religiosos (oportunistas)", é formado por palavras e expressões que possuem conotações denegridoras, em relação ao grupo que defende o Estatuto da Família. O emprego da palavra "tal", referindo-se ao Estatuto, indica um certo desrespeito, na medida em que, o predicativo do sujeito "mais uma cruzada..." confirma esse 
"tal", ou seja, a implementação do Estatuto é mais uma forma de se proceder contra os direitos humanos. O verbo "vicejar" é empregado ironicamente, uma vez que, na maioria do seu uso, refere-se ao nascimento de algo, à germinação de algo frutífero, que não é o caso do Estatuto defendido pela Carta Capital. Há ainda a possível substituição da palavra 'religiosos' por oportunistas, evidenciando a conotação negativa que a revista apresenta a bancada evangélica. No trecho: "Por ora, 'transviados' de todo o Brasil não precisam se atemorizar" é utilizado o adjetivo 'transviado' como substantivo para ironizar a forma como os "religiosos" atentem e não concordem com o Estatuto.

4. Interdiscursividade: No artigo de opinião em análise, o discurso da revista Carta Capital corrobora com seus outros discursos como visto, por exemplo, no artigo de opinião intitulado: "As vítimas da "sagrada família" que o Congresso quer criar" anterior ao artigo analisado. A revista defende um modelo diversificado de formação familiar, além de especificamente não se identificar com algumas figuras da política como o próprio Eduardo Cunha. Neste artigo, a voz do jornalista é a que direciona as vozes constituídas e marcadas as quais ele quer ativar para justificar sua verdade.

5. Modalidade: Fairclough (2003) considera o estudo da modalidade como relevante para a construção discursiva de identidades, porque 'o quanto você se compromete é uma parte significativa do que você é'. As formas verbais que constituem esse artigo são formadas, em sua maioria, por verbos no modo do indicativo, designando afirmação. O compromisso do jornalista é com a verdade, do seu ponto de vista, para isso ele utiliza verbos no presente do indicativo, apontando certeza, como também é empregado o verbo 'ser' indicando imutabilidade de fatos. Ou seja, a modalidade epistêmica no artigo é que se sobressai. Entre a modalidade objetiva e a subjetiva, esse artigo caminha para a subjetiva, uma vez que o seu grau de afinidade com o tema é explicitado, deixando claro que a afinidade expressa é a do jornalista.

\section{CONSIDERAÇÕES FINAIS}

Pretendeu-se, nesta análise de cunho investigativo-científico, discutir e refletir sobre os modos dos diversos posicionamentos das entidades jornalísticas. Através de suas ideologias, dos seus "patrocinadores", empregou-se estratégias linguísticas e discursivas semelhantes. A partir da identificação e da comparação de estratégias utilizadas na construção discursiva dos textos analisados e responsáveis pela construção dos sentidos identificados - implementação ou não do Estatuto da Família - é possível perceber que as mesmas estratégias linguístico-discursivas podem ser empregadas para transmitir pontos de vista distintos na atividade jornalística - de reportar os acontecimentos sóciopolíticos. Foi constatado que as mesmas estratégias linguístico-discursivas eleitas como categorias de análise, ajudaram, igualmente na defesa do Estatuto da Família (revista Veja, portal da Câmara e revista Gospelmais) e na discordância desse mesmo Estatuto (revista Istoé, revista Carta Capital, revista Forum e a revista Galileu). Dessa forma, a análise não apenas confirmou a imagem construída historicamente das revistas enquanto seu posicionamento relacionado à implementação ou não do Estatuto da Família, como também, mostrou que os fenômenos linguísticos não possuem em si mesmos o poder de 
manipular a palavra em prol dos interesses específicos dos locutores institucionais, pois, eles estão a serviço de quaisquer valores e posicionamentos. É o contexto de base sóciohistórica, acionado por marcas textual-discursivas, apoiado especialmente no contexto enunciativo e na história das revistas, que norteia a interpretação dos leitores em determinada direção ideológica e não em outra. Nesse sentido, para uma (in)formação mais adequada do leitor, o cotejamento, comparação de textos do conhecimento elaborado em textos cujas instituições jornalísticas possuam posicionamentos políticos distintos parece ser um caminho produtivo para um conhecimento mais amplo e mais completo.

Assim, de modo geral, percebeu-se no fazer desta pesquisa que a ciência linguística vai além da utilização de recursos linguísticos, de teorias, pois, ela é de essência empírica, sendo a base da ciência o ser humano com todas as suas idiossincrasias. E o pesquisador, cirurgião dessa ciência, não pode se deixar levar pela emoção no ato cirúrgico, tendo que ser direto e diligente, contudo, ao planejar toda a execução tem que ser levado pelo lado humano do problema, no sentido de procurar alternativas na sua área médica que levem seu paciente ao tratamento correto e adequado e isso se inicia desde o diagnóstico do sintoma. Sendo nessa analogia, o ato cirúrgico, o trabalho de pesquisa, tem que ser o mais objetiva possível, o planejamento do tratamento médico, a procura pela cura sendo humana remete a necessidade de o pesquisador reconhecer que está também lidando com problemas humanos, não relacionados, talvez, à saúde, mas ao social.

\section{REFERÊNCIAS}

BAUMAN, Z. Vida para consumo. Rio de Janeiro: Zahar, 2008.

BIROLI, F. Família: novos conceitos. São Paulo: Fundação Perseu Abramo, 2014.

BRASIL. Constituição da República Federativa do Brasil de 1988.

CASTELLS, M. O poder da identidade. $3^{\mathrm{a}}$. ed. São Paulo: Paz e Terra, 2002.

CHOULIARAKI, L.; FAIRCLOUGH, N. Discourse in late modernity: rethinking critical discourse analysis. Edinburgh: Edinburgh University Press, 1999.

EAGLETON, T. Ideologia: uma introdução. São Paulo: Ed. Unesp/Bomtempo, 1997.

FAIRCLOUGH, N. A análise crítica do discurso e a mercantilização do discurso público: as universidades. Em: MAGALHÃES, C.M. (Orga.). Reflexões sobre a análise crítica do discurso. Belo Horizonte: FALE/UFMG, 2001.

FAIRCLOUGH, N. Discurso e mudança social. Brasília: Editora da UnB, 2001a.

GIDDENS, A. As consequências da modernidade. São Paulo: Unesp, 1991.

HALL, S. A Identidade Cultural na Pós-Modernidade. Rio de Janeiro: DP\&A, 2000.

HALLIDAY, M.A.K. Introduction to functional grammar. London: Edward Arnold, 1985.

RESENDE, Viviane de Melo; RAMALHO, Viviane. Análise de discurso (para a) crítica: o texto como material de pesquisa. Campinas: Pontes, 2011.

THOMPSON, John Brookshire. Ideologia e cultura moderna: teoria social na era dos meios de comunicação de massa. 5a. ed. Petrópolis: Vozes, 1995.

TREVISAN, Janine. A Frente Parlamentar Evangélica: força política no estado laico brasileiro.

Numen, Juiz de Fora, vol. 16, n. 1, p. 581-609, 2013.

VAN DIJK, Teun. Discurso e poder. São Paulo: Contexto, 2008. 
Artigo recebido em: fev. de 2019.

Aprovado e revisado em: ago. de 2019.

Publicado em: dezembro de 2019.

Para citar este texto:

LIMA, Fábio Fernando. A materialização discursiva da exclusão social no jornalismo impresso paulista. Entremeios [Revista de Estudos do Discurso, ISSN 2179-3514, on-line, www.entremeios.inf.br], Seção Estudos, Programa de Pós-Graduação em Ciências da Linguagem (PPGCL), Universidade do Vale do Sapucaí (UNIVÁS), Pouso Alegre (MG), vol. 19, p. 145-158, jul. - dez. 2019.

DOI: http://dx.doi.org/10.20337/ISSN2179-3514revistaENTREMEIOSvol19pagina145a158 